\title{
Advanced Techniques for Morphometric Analysis in Fish
}

\section{Mojekwu TO"* and Anumudu $\mathrm{Cl}^{2}$}

${ }^{1}$ Department of Biotechnology Unit, Nigerian Institute for Oceanography and Marine Research, Nigeria

${ }^{2}$ Department of Zoology, University of Ibadan, Nigeria

\begin{abstract}
Information on the biology and population structure of any species is a prerequisite for developing management and conservation strategies. Morphometric characters of fish are the measurable characters common to all fishes. Some arbitrarily selected points on a fish body known as landmarks help the individual fish shape to be analyzed. A landmark is a point of correspondence on an object that matches between and within populations. Advanced techniques for morphometric analysis offers more efficient and powerful tools in identify differences between fish populations, detecting differences among groups and to differentiate between species of similar shape. Morphometric methods such as univariate comparisons, bivariate analyses of relative growth pattern and a series of multivariate methods have been developed and applied to discriminate stocks. The use of multivariate techniques such as principal components and discriminant analyses to quantify morphometric variables are also receiving increased attention in stock identification. Some of the advanced techniques developed for morphometric analysis in fish population are Truss network measurement, Image analysis- Univarite, Bivariate, and Multivariate, Principal Component Analysis (PCA).
\end{abstract}

Keywords: Biology; Fishery science; Morphometrics method; Fish recognition and monitoring

\section{Introduction}

The field of fishery science has employed many tools such as genetics and morphometric to differentiate fish population [1]. Morphometrics may be defined as a more or less interwoven set of largely statistical procedures for analyzing variability in size and shape of organs and organisms. Morphometric differences among stocks of a species are recognized as important for evaluating the population structure and as a basis for identifying stocks [2,3]. Morphometric measurements are widely used to identify differences between fish populations [4-6]. Truss network systems constructed with the help of landmark points are also a powerful tool for stock identification. Some arbitrarily selected points on a fish body known as landmarks help the individual fish shape to be analyzed. A landmark is a point of correspondence on an object that matches between and within populations [7].

\section{Materials and Methods}

Morphometric analysis offers more efficient and powerful techniques, such as image analysis, for detecting differences among groups and to differentiate between species of similar shape [8].

Image analysis systems played a major role in the development of morphometric techniques, boosting the utility of morphometric research. The characteristics may be more applicable for studying short term, environmentally induced disparities, stock identification $[9,10]$, species differences, practical morphology and improved fisheries management [11].

Some morphometric methods have also been developed and applied to discriminate stocks such as univariate comparisons, bivariate analyses of relative growth pattern and a series of multivariate methods [12]. On the other hand, the use of multivariate techniques such as principal components and discriminant analyses to quantify morphometric variables is receiving increased attention in stock identification [13-16].

Advanced techniques for morphometric analysis in fish population includes:

\section{Truss network measurements}

Truss network systems constructed with the help of landmark points are powerful tools for stock identification of fish species [17]. A sufficient degree of isolation may result in notable morphological, meristic, and shape differentiation among stocks of a species which may be recognizable as a basis for identifying the stocks. The characteristics may be more applicable for studying short-term, environmentally induced disparities, and the findings can be effectively used for improved fisheries management [18-21].

The truss network system can effectively be used to distinguish between the hatchery and wild stocks. It has been also successfully utilized to differentiate and identify stock of the horse mackerel Trachurus trachurus and the Japanese threadfin bream Nemipterus japanicus [22]. It has been used to show more-significant differences between two completely different habitats i.e., in an open and closed water habitat [23].

Truss measurements are a powerful tool for the analysis of shape, and generally are designed to cover all, or most, of the animal's body [24]. According to Dwivedi and Dubey [25] the truss network is more useful and an effective strategy for the descriptions of shape; it has better data collection and diversified analytical tools in comparison to traditional morphometrics method. Thus it is able to discriminate phenotypic stock because the configuration of the constructed landmarks covers the entire fish body with no loss of information, and it is more sensitive to change [22].

Trust network measurement in fish involves anaesthetizing with

*Corresponding author: Mojekwu TO, Department of Biotechnology Unit, Nigerian Institute for Oceanography and Marine Research, Nigeria, E-mail: tonyystone@yahoo.com

Received April 13, 2015; Accepted May 13, 2015; Published June 30, 2015

Citation: Mojekwu TO, Anumudu Cl (2015) Advanced Techniques for Morphometric Analysis in Fish. J Aquac Res Development 6: 354. doi:10.4172/21559546.1000354

Copyright: (c) 2015 Mojekwu TO, et al. This is an open-access article distributed under the terms of the Creative Commons Attribution License, which permits unrestricted use, distribution, and reproduction in any medium, provided the original author and source are credited. 


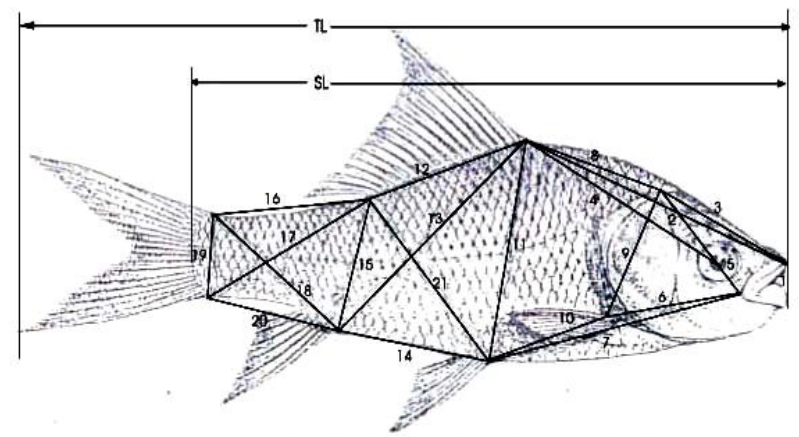

Figure 1: Typical Truss Morphometric Network (TMN) of Indian Major Carp.

benzocaine (ethyl-p-amino-benzoate) [26] before being weighed and measured Figure 1. The first step is to take and record the standard length (LS), post-orbital length (LPO) and maximum body width of the fish. Standard length will be taken from the tip of the upper jaw to the base of the caudal peduncle. Then a truss network is constructed between landmark points, homologous throughout the population, chosen because they describe the major features of the fish (Figure 1). The landmarks were linked closely to the skeletal structure of fish and were easily observed by eye.

Truss lengths measured between these landmark points should either lie on curved surfaces or be on straight lines lying on a flat plane $[27,28]$. The distances were measured with the help of vernier callipers (RS and Cam lab) or brass divider accurately to $0.1 \mathrm{~mm}$ [28]. Measuring four fishes repeatedly will help assess the accuracy of measurements and comparing results. Measurement errors were calculated by taking the mean of the standard deviation of the measurements for each fish. The relative error is the percentage of the mean truss length that the tabulated measurement error represents.

Legends: 1 . Mouth tip to premaxilla (MTPM), 2. Mouth tip to dorsal fin (MTDF), 3. Mouth tip to operculum top (MTOT), 4. Pre maxilla to dorsal fin (PMDF), 5. Pre maxilla to operculum tip (PMOT), 6. Pre maxilla to pectoral fin (PMPC), 7. Pre maxilla to pelvic fin (PMPV), 8. Dorsal fin to operculum tip (DFOT), 9. Pectoral fin to operculum tip (PCOT), 10. Pectoral fin to pelvic fin (PCPV), 11. Dorsal fin to pelvic fin (DFPV), 12. Dorsal fin front to dorsal fin back (DFDB), 13. Dorsal fin to anal fin (DFAF), 14. Pelvic fin to anal fin (PVAF), 15. Dorsal back to anal fin (DBAF), 16. Dorsal fin back to caudal top (DBCT), 17. Dorsal back to caudal bottom (DBCB), 18. Anal fin to caudal top (AFCT), 19. Caudal top to caudal bottom (CTCB), 20. Anal fin to caudal bottom (AFCB), 21. Dorsal fin back to pelvic fin (DBPV).

\section{Image analysis morphormetric methods}

The development of image analysis systems has facilitated progress and diversification of morphometric methods and expands the potential for using morphometry as a tool for stock identification. Traditional multivariate morphometrics, accounting for variation in size and shape, have successfully discriminated many fish stocks. However, traditional methods have been enhanced by image processing techniques, through better data collection, more effective descriptions of shape, and new analytical tools. (Properly calibrated coordinates of morphometric locations, or landmarks', are generally more efficient and precise than manual distance measurements. Truss networks' of distances between landmarks coordinates provide more comprehensive coverage of form for greater discriminating power $[9,10]$. Image analysis systems also allow more advanced geometric morphometrics, which include outline methods and landmark methods [29]. Unfortunately, few stock identification studies have applied outline methods, and landmark methods have not been used to discriminate fishery stocks.

Image analysis is the extraction of meaningful information from images; mainly from digital images by means of digital image processing techniques [30]. Image analysis tasks can be as simple as reading bar coded tags or as sophisticated as identifying a person from their face. Computers are indispensable for the analysis of large amounts of data, for tasks that require complex computation, or for the extraction of quantitative information. There are many different techniques used in automatically analysing images. Each technique may be useful for a small range of tasks, however there still aren't any known methods of image analysis that are generic enough for wide ranges of tasks, compared to the abilities of a human's image analysing capabilities. Examples of image analysis techniques in different fields include: 2D and $3 \mathrm{D}$ object recognition, image segmentation, motion detection e.g. tracking, video, flow, analysis, Estimation, automatic [31].

From the previous works, there are a lot of papers discussing methods to measure the various sizes of fish [32-34] from a digital image. Naiberg and Little [32] developed a size assessment system underwater using model-based recognition and stereoscopic vision. Model-based recognition is used to locate the object and stereo vision system to determine distance and sizes given stereo video input. However, the stereo vision system is very expensive and the matching procedures also still have error and poor image quality that can affect the accuracy of measurement.

Another method is automated Fish Recognition and Monitoring (FIRM) proposed by Lee et al. [33]. He focuses on comparison of technique to shape matching but did not focus to obtain the size of fish. This method has five main processing steps: image acquisition, object detection algorithm detects the presence of an object (DMA), identifying the fish with object contour extraction used Canny Edge operator and identification, Tracking of the fish object determines the location of the fish , triggering the recognition process when an image of the whole fish can be acquired. The measurement size and species of fish used shape-based recognition. This method is suitable for fish in an aquarium. Besides that, White et al., [34] measured species and fish length by implementing computer vision for sorting fish in industrial area. Such method must have laboratory equipped with a conveyor belt and other hardware such as pc, lamp and sensor as in Figure 2.

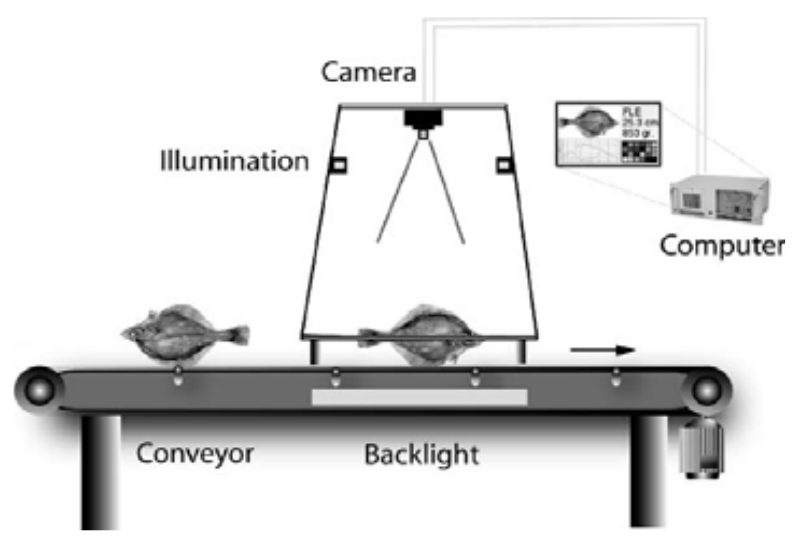

Figure 2: Modern Hardware used for measuring species and fish length by implementing computer vision for sorting fish in industrial areas. 


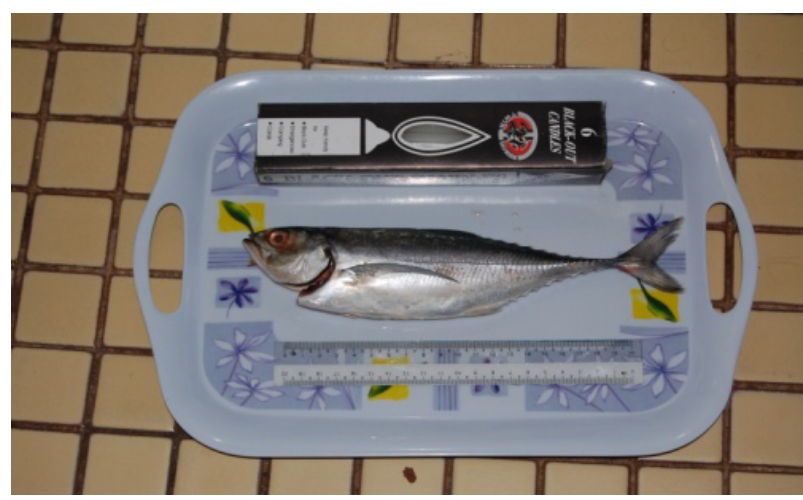

Figure 3: Method of analysing digital object using Object Reference by Pickle.

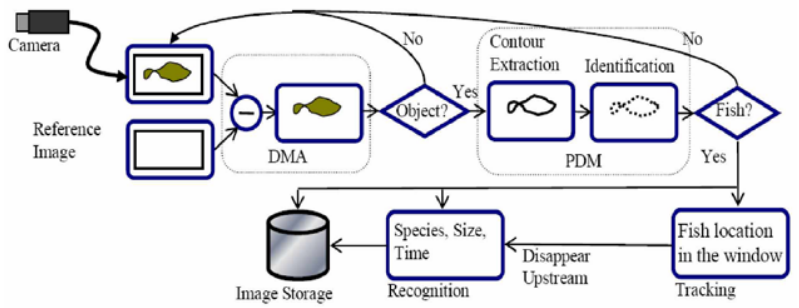

Figure 4: Fish Recognition and monitoring processing algorithm flowchart.

This method may not be suitable for studies in which one needs to measure the fish length rapidly without going to laboratory because the fisherman sells the fish as soon as possible. It is also an inexpensive, accurate and short time method of measuring length of fish.

Hsiu [35] solve the problem of Pickle's method which measure size of object from digital without object reference (Figure 3). Hsiu methods obtain size of object directly from digital image by using equation magnification and software image viewing program [35]. The equation magnification is used to obtain ratio for actual object value and software image viewing program to detect edge automatically.

The object is a very simple feature (Figure 4). Detecting fish image is usually difficult because head and tail of fish have curve and corner which must be detected accurately in calculating fish size. Fish can be detected using maximizing bending ratio and curvature to detect corner as done by Serkan et al. [36].

From the Hsiu's and Serkan's method, a new method was developed for measuring fish length from digital image by combining both of the method. Hsiu's method has been used to obtain the actual length of fish and Serkan's method has been used for image processing. The new method is used to measure length of fish from digital image. Whole fish features including fish contour and significant landmark points can then be extracted for analysis. Shape-based recognition can be performed to obtain size and species information.

After the image is processed to obtain corner detection at head and tail, the image will be processed to obtain number of pixel from corner head to corner tail [37]. The image of fish length will be obtained when the number of pixels is multiplied with pixel size which is gotten from image. The actual fish length is calculated with equation of "object distance/object height=image distance/image height". Wherein actual of fish length=object height by image height=image of fish length and image distance $=$ focus length.

This new method is an automated method of measuring the length of a fish using equation magnification and image processing which has high potential to be commercialized given its high reliability, durability and accuracy factors; as well as minimizing cost and time needed for such task. This means that it has to be able to measure length of the fish without having a person holding the fish. The idea is to capture the image of the fish using a camera that uploads the picture to the software to evaluate the length of the fish. The impact of the contribution of this new method will ensures stability and security of a country's main source of protein.

\section{Univariate, bivariate, and multivariate morphormetric analysis}

The earliest analyses of morphometric variables for stock identification were univariate comparisons, but these were soon followed by bivariate analyses of relative growth to detect ontogenetic changes and geographic variation among fish stocks. As the field of multivariate morphometrics grew, a set of multivariate methods was applied to quantify variation in growth and form among stocks.

Univariate analysis is the simplest form of quantitative (statistical) analysis [38]. The analysis is carried out with the description of a single variable in terms of the applicable unit of analysis. Univariate analysis contrasts with bivariate analysis - the analysis of two variables simultaneously - or multivariable analysis - the analysis of multiple variables simultaneously [38]. Univariate analysis is commonly used in the first, descriptive stages of research, before being supplemented by more advanced, inferential bivariate or multivariate analysis $[39,40]$

In univariate analysis, the measure of central tendency is an average of a set of measurements, the word "average" being variously construed as (arithmetic) mean, median, mode or another measure of location, depending on the context. For a variable measured on an interval scale, such as temperature on the Celsius scale, or on a ratio scale, such as temperature on the Kelvin scale, the median or mean can also be used [38].

Bivariate analysis is one of the simplest forms of quantitative (statistical) analysis [41]. It involves the analysis of two variables often denoted as (X, Y), for the purpose of determining the empirical relationship between them. In order to see if the variables are related to one another, it is common to measure how those two variables simultaneously change together. Bivariate analysis can be helpful in testing simple hypothesis of association and causality- checking to what extent it becomes easier to know and predict a value for the dependent variable if we know a case's value of the independent variable. The major differentiating point between univariate and bivariate analysis, in addition to the latter's looking at more than one variable, is that the purpose of a bivariate analysis goes beyond simply descriptive: it is the analysis of the relationship between the two variables. Bivariate analysis is a simple (two variable) special case of Multivariate analysis (where multiple relations between multiple variables are examined simultaneously) [41]. Common forms of bivariate analysis involve creating a percentage table or a scatter plot graph and computing a simple correlation coefficient. The type of analyses that are suited to particular pairs of variables vary in accordance with the level of measurement of the variables of interest (e.g. nominal/categorical, ordinal, interval/ratio). If the dependent variable-the one whose value is determined to some extent by the other, independent variable- is a 
categorical variable, such as the preferred species of fish, then probit or logit regression (or multinomial probit or multinomial logit) can be used. If both variables are ordinal, meaning they are ranked in a sequence as first, second, etc., then a rank correlation coefficient can be computed. If just the dependent variable is ordinal, ordered probit or particular type or causality known as Granger causality can be tested for, and vector auto regression can be performed to examine the intertemporal linkages between variables.

Multivariate statistics encompasses the simultaneous observation and analysis of more than one outcome variable [42]. The application of multivariate statistics is multivariate analysis. Multivariate statistics concerns understanding the different aims and background of each of the different forms of multivariate analysis, and how they relate to each other [42]. The practical implementation of multivariate statistics to a particular problem may involve several types of univariate and multivariate analyses in order to understand the relationships between variables and their relevance to the actual problem being studied.

In addition, multivariate statistics is concerned with multivariate probability distributions, in terms of both how these can be used to represent the distributions of observed data; how they can be used as part of statistical inference, particularly where several different quantities are of interest to the same analysis [43]. Certain types of problem involving multivariate data, for example simple linear regression and multiple regression, are not usually considered as special cases of multivariate statistics because the analysis is dealt with by considering the (univariate) conditional distribution of a single outcome variable given the other variables [43].

\section{Principal component analysis (PCA)}

PCA is a multivariate statistical technique that uses orthogonal transformation to convert a set of correlated variables into a set of orthogonal uncorrelated axes called principal components [44-46]. PCA enables condensation of data on a multivariate phenomenon into its main, representative features by projection of the data into a two- dimensional presentation. The two created resource axes are independent, and although they reduce the number of dimensionsi.e. the original data complexity -they maintain much of the original relationship between the variables: i.e., information or explained variance [47]. This is helpful in focusing attention on the main characteristics of the phenomenon under study. It is convenient that if the first few principal components (PCs) explain a high percentage of variance,environmental variables that are not correlated with the first few PCs can be disregarded in the analysis [48]. In addition, applying PCA has become relatively user- friendly because of the numerous programs that assist in carrying out the computational procedure with ease [49-52].

PCA has been widely used in various fields of investigation and for different tasks. Many authors have used PCA for its main purpose i.e., to reduce strongly correlated data groups or layers. These studies concern either environmental variation [53-57]; the investigated species or community characteristics Youlatos [58]; Kitahara and Fujii [59]; Xiaoyun et al. [60]; Zhao et al. [61]; Noura et al. [62] or both, sometimes in combination with Detrended Correspondence Analysis (DCA), Canonical Correspondence Analysis (CCA), and other ordination methods [63-65].

The application of PCA has helped in aquatic habitat studies; it has been applied to evaluate aquatic habitat suitability, its regionalization, analysis of fish abundance, their seasonal and spatial variation, lake ecosystem organization change etc. [66-68]. However, it has been often applied in analyzing farming system changes [69]. In many cases, PCA has been used as a source or supporting analysis in the performance of more complex analysis, such as the study of adaptive fish radiation, strongly influenced by trophic niches and water depth [70], predicting the potential spatial extent of species invasion [71] and multi-trait analysis of intra- and interspecific variability of plant traits [72].

\section{Conclusion}

Morphometrics adds a quantitative element to descriptions, allowing more rigorous comparisons. It enables one to describe complex shapes in a rigorous fashion and permits numerical comparison between different forms. Advancements in morphometrics uses powerful tools for testing and displaying differences in shape, isolate shape from size variation and identifying stocks of specie with unique morphological characteristics. This has enabled a better management of species subunits and ensures better management of the fishery resources. These morphormetric advancements techniques analysis in fish population includes: Truss network measurement, Image analysisUnivarite, Bivariate, and Multivariate, Principal Component Analysis (PCA).'Trust Network System' has emerged as a new tool with more effective strategies for descriptions of shape, better data collection and diversified analytical tools. Recent developments made in the discipline of morphormetric differentiation in body shape among fish populations showed that the truss based techniques is more effective than manual distance measurement for the management of fishery resources throughout the world. When combined with multivariate statistical methods (e.g. Principal Component Analysis, Cluster Analysis etc) they offer powerful tool for testing and displaying differences in shape.

\section{References}

1. Mir JI, Sarkar UK, Dwivedi AK, Gusain OP, Jena JK (2013) Stock structure analysis of Labeorohita (Hamilton, 1822) across the Ganga basin (India) using a truss network system. Journal of Applied Ichthyology 29: 1097 -1103.

2. Turan (2004a) Stock identification of Mediterranean horse mackere (Trachurusmediterraneus) using morphometric and meristic characters. Journal of Mar. Science 61:774-781.

3. Cadrin SX, Friedland KD (1999) The utility of image processing techniques for morphometric analysis and stock identification. Fisheries Research 43: 129139

4. Cheng Q, Lu D, Ma L (2005) Morphological differences between close populations discernible by multivariate analysis: A case study of genus Coilia (Teleostei: Clupeiforms). Aquatic Living Resources 18: 187-92.

5. Buj I, Podnar M, Mrakovcic M, Caleta M, Mustafic P, et al. (2008) Morphologica and genetic diversity of Sabanejewiabalcanicain Croatia. Folia Zooology $57: 100-110$

6. Torres RGA, Gonzalez PS, Pena SE (2010) Anatomical, histological and ultraestructural description of the gills and liver of the Tilapia (Oreochromisniloticus). International Journal of Morphology 28: 703-12.

7. Hossain MAR, Nahiduzzaman M, Saha D, Khanam MUH, Alam MS (2010) Landmark- based morphometric and meristic variations of the endangered carp,Kalibauslabeocalbasu,from stocks of two isolated rivers,thejamuna and Halda, and a hatchery. Zoological studies 49: $556-563$.

8. Costa C, Loy A, Cataudella S, Davis D, Scardi M(2006) Extracting Fish Size Using Dual Underwater Cameras. Aquacultural Engineering 35: 218-227.

9. Bronte CR, Moore SA (2007) Morphological Variation of Siscowet Lake Trout in Lake Superior. Transactions of the American Fisheries Society 136: 509-517.

10. Shao Y, Wang J, Qiao Y, He Y, Cao W (2007) Morphological variability between wild populations and inbred stocks of a Chinese minnow, Gobiocyprisrarus. Zoological Science 24: 1094-1102.

11. Turan C, Erguden D, Gurlek M, BasustaN,Turan F (2004) Morphometric structuring of the anchovy (EngraulisencrasicolusL.) in the Black, Aegean and 
northeastern Mediterranean Seas. Turkish Journal of Vetinary Animal Science 28:865-871.

12. Cadrin SX (2000) Advances in morphometric identification of fishery stocks. Reviews in Fish Biology and Fisheries 10: 91-112.

13. Kusznierz J ,Kotusz J, Kazak M , Popiolek M, Witkowski A (2008) Remarks on the morphological variability of the Arctic charr, Salvelinusalpinus(L.) from Spitsbergen. Polish Polar Research 29: 227-236.

14. Specziar A, Bercsenyi M, Muller T (2009) Morphological characteristics of hybrid pikeperch (Sander luciopercax Sander volgensis) (Osteichthyes, Percidae). Acta Zoo. Hung 55: 39-54.

15. Yakubu A, Okunsebor SA (2011) Morphometric differentiation of two Nigerian fish species (Oreochromisniloticusand Latesniloticus) using principal components and discriminant analysis. International Journal of Morphology29:1429-1434.

16. Cronin Fine L, Stockwell JD, Whitener ZT, Labbe EM, Willis TV, et al. (2013) Application of Morphometric Analysis to Identify Alewife stock structure in the Gulf of Maine. Marine and Coastal Fisheries. Dynamics, Management, and Ecosystem Science 5: 11-20.

17. Turan C, Erguden D and Gurlek M (2004b) Genetic and morphologic structure of Liza abu(Heckel, 1843) populations from the Rivers Orontes, Euphrates and Tigris. Turkish Journal of Vetinary Animal Science 28: 729-734.

18. Sajina AM, Chakraborty SK, Jaiswar AK, Pazhayamadom DG, Sudheesan D (2011) Stock structure analysis of Indian Mackerel, Rastrelligerkanagurta (Cuvier,1816) along the Indian coast. Asian Fisheries Science 24: 331-342.

19. Merz JE, Garrison TM, Bergman PS, Blankenship S, Garza JC (2014) Morphological Discrimination of Genetically Distinct Chinook Salmon Populations: an Example from California's Central Valley. North American Journal of Fisheries Management 34: 1259-1269.

20. Pazhayamadom DG, Chakraborty SK, Jaiswar AK, Sudheesan D, Sajina AM (2015) Stock structure analysis of Bombay duck (Harpadonnehereus Hamilton,1822) along the Indian coast using truss network morphometrics. Journal of Applied Ichthyology 31: 37- 44.

21. Wiadnya DGR, Widodo D, Soemarno S (2015) Intra- species variations of photopectoralisbindus (Family:Leiognathidae) collected from two geographica areas in East Java,Indonesia. Journal of Biodiversity and Environmental Sciences 6:160-168.

22. Lim TY (2008) Biology of the Bettapucnaxgroup from Johore. Universiti Sains Malaysia, Penang.

23. Hossain MAR, Nahiduzzaman M, Saha D, Khanam MUH, Alam MS (2010) Landmark- based morphometric and meristic variations of the endangered carp,Kalibauslabeocalbasu, from stocks of two isolated rivers, the jamuna and Halda, and a hatchery. Zoological studies 49: $556-563$.

24. Strauss RE, Bookstein FL (1982) The truss: body form reconstruction in morphometrics. Systematic Zoology 31:113-135.

25. Dwivedi AK, Dubey VK (2013) Advancements in morphormetric differentiation: a review on stock identification among fish populations. Review in Fish Biology and Fisheries 23:23-39.

26. Ross LG, Ross B (1999) Anaesthetics and Sedative Techniques for Aquaculture Animals.

27. Hockaday S, Beddow S, Stone M, Hancock P, Ross LG (2000) Using truss networks to estimate the biomass of Oreochromisniloticus and to investigate shape Characteristics. Journal of Fish Biology 57: 981-1000.

28. Ujiania NC, Kohli MPS (2011) Landmark-based morphormetric analysis for selected species of Indian Major Carp (Catlacatla, Ham. 1822). International Journal of Food, Agriculture and Veterinary Sciences 1:64-74.

29. Toh YH, Ng TM, Liew BK (2009) Computational Intelligence and Software Engineering. IEEE International Conferenceat Wuhan 3: 1-5.

30. Solomon CJ, Breckon TP (2010) Fundamentals of Digital Image Processing: A Practical Approach with Examples in Matlab.

31. Hay GJ, Castilla G (2008) Geographic Object-Based Image Analysis (GEOBIA): A new name for a new discipline.

32. Naiberg A, Little JJ (1994) A Unifed Recognition and Stereo Vision Systemfor size assessment of fish.

33. Lee DJ, Schoenberger R, Shiozawa D, Xu X, Zhan P (2008) Contour Matching for a Fish Recognition and Migration Monitoring System. SPIE Optics East, Two and Three-Dimensional Vision System for Inspection, Control, and Metrology.

34. White DJ, Svellingen C, Strachan NJC (2006) Automated Measurement of Species and Length of fish by Computer Vision. Fisheries Research 80 203-210.

35. Hsu HO (2008) Method for Calculating Distance and Actual Size of Shot Object.

36. Serkan K, Hantao L, Miguel F, Moncef G (2007) An Efficient Approach for Boundary Based Corner Detection by Maximizing Bending Ratio and Curvature, 9th International Symposium onSignal Processing and Its Applications.

37. Chanda B (2008) Morphological Algorithms for Image Processing. IETE Technical Review 25: 9-18.

38. Babbie E R(2009) The Practice of Social Research. Wadsworth Publishing,USA

39. Bernard HR (2006) Research methods in anthropology: qualitative and quantitative approaches.

40. Cooper A, Weekes TJ (1983) Data, models, and statistical analysis, Barnes\& Noble Books, USA.

41. Earl RB (2009) The Practice of Social Research. Wadsworth Publishing,USA.

42. Hidalgo B, Goodman M (2013) Multivariate or multivariable regression? American journal of public health 103:39- 40.

43. Johnson RA, Wichern DW (2007) Applied Multivariate Statistical Analysis Prentice Hall6:77-153.

44. Robertson MP, Caithness N,Villet MH (2001) A PCA-based modeling technique for predicting environmental suitability for organisms from presence records. Diversityand Distributions 7: 15-27.

45. Legendre P, Legendre L (1998) Numerical Ecology. Elsevier 17: 853.

46. Gotelli NJ, Ellison AM (2004) A Primer of Ecological Statistics.

47. Litvak MK, Hansell RIC (1990) A community perspective on the multidimensional niche. J Animal Ecology 59: 931-940.

48. Toepfer CS, Williams LR, Martinez AD, Fisher WL (1998) Fish and habitat heterogeneity in four streams in the central Oklahoma/Texas plains ecoregion. Proceedings of the Oklahoma Academy of Science 78: 41-48.

49. Dolédec S, Chessel D, Gimaret-Carpentier C (2000) Niche Separation in Community Analysis: A New Method. Ecology 81: 2914-2927.

50. Guisan A, Zimmerman NE (2000) Predictive habitat distribution models in ecology. Ecological Modelling 135:147-186.

51. Rissler LJ, Apodaca JJ (2007) Adding more ecology into species delimitation: Ecological niche models and phylogeography help define cryptic species in the black salamander (Aneidesflavipunctatus). Systematic Biology 56: 924-942.

52. Marmion M, Parviainen M, Luoto M, Heikkinen RK, Thuiller W (2009) Evaluation of consensus methods in predictive species distribution modelling. Diversity andDistributions 15: 59-69.

53. Glor RE, Warren D (2010) Testing ecological explanations for biogeographic boundaries. Evolution 65: 673-683.

54. Novak T, Thirion C, Janžekovič F (2010) Hypogeanecophase of three hymenopteran species in Central European caves. Italian J Zoology 77: 469475

55. Faucon MP, Parmentier I, Colinet G, Mahy G, Luhembwe M N (2011) May rare metallophytes benefit from disturbed soils following mining activity? The Case of the Crepidorhopalontenuisin Katanga (D. R. Congo). Restoration Ecology 19: $333-343$

56. Adamu M (2012) Identification of Anthropogenic influences on water quality of Jakara River, northwest Nigeria. J Applied Sciences in Environmental Sanitation 7: $11-20$

57. Andem AB, Okafor KA, Ekanem SB (2015) Factor Analysis and PhysicoChemical characteristics of Calabar River, Southern Nigeria. International Journal of scientific and Technology Research 4:25- 28.

58. Youlatos D (2004) Multivariate analysis of organismal and habitat parameters in two neotropical primate communities. American J Physical Anthropology 123: $181-194$

59. Kitahara M, Fujii K (2005) Analysis and understanding of butterfly community 
Citation: Mojekwu TO, Anumudu Cl (2015) Advanced Techniques for Morphometric Analysis in Fish. J Aquac Res Development 6: 354. doi:10.4172/2155-9546.1000354

Page 6 of 6

composition based on multivariate approaches and the concept of generalist/ specialist strategies. Entomological Sci 8: 137-149.

60. Xiaoyun FB, Cui H, Zhao Z, Zhiming Z, Honggang Z (2010) Assessment of river water quality in Pearl River Delta using multivariate statistical techniques. Procedia Environ Sci 2: 1220-1234.

61. Zhao J, Fu G, Lei K, Li Y (2011) Multivariate analysis of surface water quality in the three Georges area of China and implications for water management. J Environ Sci 23: 1460-1471.

62. Noura S, Mustapha B, Moncef B (2015) Taxonomic diversity and benthic community structures of watersheds of Medjerda and Joumine (North east of Tunisia).Inter Res J Earth Sci 3: 24 -30.

63. Warner BG, Asada T, Quinn NP (2007) Seasonal influences on the ecology of testateamoebae (Protozoa) in a small Sphagnum peatland in Southern Ontario, Canada. Microbial Ecology 54: 91-100.

64. Gonzalez-Cabello A, Bellwood DR (2009) Local ecological impacts of regional biodiversity on reef fish assemblages. J Biogeography 36: 1129-1137.

65. Mezger D, Pfeiffer M (2011) Partitioning the impact of abiotic factors and spatial patterns on species richness and community structure of ground ant assemblages in four Bornean rainforests. Ecography 34: 39-48.
66. Ahmadi-Nedushan B, St-Hilaire A, Bérubé $M$, Robichaud $E$, Thiémonge $N$, et al. (2006) A review of statistical methods for the evaluation of aquatic habita suitability for instream flow assessment. River Research and Applications 22 503-523.

67. Catalan J, Barbieri MG, Bartumeus F, Bitušk P, Botev I, et al. (2009) Ecological thresholds in European alpine lakes. Freshwater Biology 54: 2494-2517.

68. Eze EB, Efiong J ( 2010) Morphometric parameters of calabar River basin Implication for Hydrologic Processess. J Geography and Geology 2: 19161920.

69. Amanor KS, Pabi O (2007) Space, time, rhetoric and agricultural change in the transition zone of Ghana. Human Ecology 35:51-67.

70. Clabaut C, Bunje PM, Salzburger W, Meyer A (2007) Geometric morphometric analyses provide evidence for the adaptive character of the Tanganyikan cichlid fish radiations. Evolution 61: 560-578.

71. Broennimann $O$, Treier U A, Müller-Schärer $H$, Thiuller $W$, Peterson AT, et al (2007) Evidence of climatic niche shift during biological invasion. Ecology Lett. 10: 701-709.

72. Albert CH, Thuiller W, Yoccoz NG, Douzet R, Aubert S, et al. (2010) Amultitrait approach reveals the structure and the relative importance of intra- vs -interspecific variability in plant traits. Functional Ecology 24: 1192-1201. 